\title{
Interleukin-1 $\alpha$ and tumor necrosis factor- $\alpha$ expression on the compressed side of gingiva during orthodontic tooth movement
}

\author{
Hyoung-Seon Baik ${ }^{1}$, Chong-Kwan Kim², Won Hee Lim $^{3}$, Youn Sic Chun ${ }^{3}$ \\ ${ }^{1}$ Department of Orthodontics, College of Dentistry, Yonsei University, Seoul, Korea \\ ${ }^{2}$ Department of Periodontics, College of Dentistry, Yonsei University, Seoul, Korea \\ ${ }^{3}$ Division of Orthodontics, Department of Dentistry, Ewha Womans University, Seoul, Korea \\ Email:wonheelim@gmail.com
}

Received 17 May 2012; revised 25 June 2012; accepted 2 July 2012

\begin{abstract}
Objectives: The aim of this study was to investigate the effect of orthodontic loading on the expression of interleukin-1 $\alpha(\mathrm{IL}-1 \alpha)$ and tumor necrosis factor- $\alpha$ $(\mathrm{TNF}-\alpha)$ in compressed gingiva. Materials and Methods: Twenty-four male Wistar rats were used with four rats as controls at day $\mathbf{0}$. In ten rats, corticotomy was performed on either left or right side and the remaining side was served as control, and killed at 7 and 14 days. In the remaining ten rats, maxillary right and left first molars were moved orthodontically with a constant force of $20 \mathrm{~g}$; appliance and appliance in conjunction with cortictomy (appliance-corticotomy) were sequentially alternated between left and right sides and euthanized at 7 and 14 days. Real time polymerase chain reactions of compressed gingiva excised from the euthanized rats was performed to measure mRNA expressions of IL- $1 \alpha$ and TNF- $\alpha$. Results: There were no significant differences in the expression of IL-1 $\alpha$ between all the groups. On the other hand, TNF- $\alpha$ from the pressure side in the appliance group and the appliance in conjunction with corticotomy group showed significant increase on the 7th day compared to that of either control or corticotomy group. Conclusions: Orthodontic loading induced the elevation of TNF- $\alpha$ in compressed gingiva.
\end{abstract}

Keywords: Tooth Movement; Gingiva; Compressed Side; IL- $1 \alpha$; TNF- $\alpha$

\section{INTRODUCTION}

Pressure within the periodontal ligament (PDL) space induced by orthodontic forces results in vascular compression, which leads to cellular activation and the release of pro-inflammatory molecules such as prostaglandins and cytokines [1]. Interleukin-1 (IL-1) and tu- mor necrosis factor- $\alpha$ (TNF- $\alpha$ ) are known potent cytokines involved in the initiation of bone resorption [2-6]. According to Davidovitch, there were marked increases in the IL- 1 and TNF- $\alpha$ staining intensities in the periodontal ligament (PDL) and in the alveolar bone during orthodontic tooth movement in cats [7]. In human gingival crevicular fluid (GCF), elevated IL-1 and TNF- $\alpha$ levels during orthodontic tooth movement have also been reported [8-10]. This implies that the expression of cytokines in GCF is related to a biological connection between the PDL and GCF following force loading.

In addition to detection of these cytokines in GCF, gingival tissue contours are modified clinically as well as histologically during orthodontic tooth movement [11]. In some cases, an excess of gingiva and/or the presence of hyperplastic gingiva can also interfere with tooth movement [11]. Thus, it seems that gingiva have a crucial role during tooth movement. Moreover, it has been speculated that there is interaction between the gingiva and the PDL in adult periodontitis since gingival inflammation is associated with activation of inflammatory cytokines and/or matrix metalloproteinases in the PDL [12].

Although there are many reports on cytokine production in alveolar bone and in PDL during tooth movement, there are few studies regarding cytokine production in gingival $[13,14]$. The amount of IL- $1 \beta$ in human gingival fibroblasts was reported to increase during orthodontic loading [13]. Another study demonstrated that IL- $1 \alpha$ and TNF- $\alpha$ levels increased in the gingiva along the compressed side as well in the PDL and alveolar bone after tooth movement [14]. These results implied a substantial inflammatory reaction over an extended area upon orthodontic loading. Thus, investigation of reactions in soft tissues may improve the understanding of biologic events in surrounding tissues during tooth movement.

Exploration of cellular or sub-cellular changes in gin- 
gival tissues following different amounts of tooth movement during the same period would help reveal a portion of the biological connections between the gingiva and the PDL. To assist in that exploration, tooth movement in conjunction with corticotomy was included in this study. Comparisons of gingival tissue following tooth movement with that following tooth movement in conjunction with corticotomy were undertaken to show changes in gingiva related to bone remodeling effects. The effects of orthodontic force on the expression of IL- 1 and TNF- $\alpha$ along the compressed side of the gingiva were evaluated using real time polymerase chain reaction (PCR). IL-1 and TNF- $\alpha$ expression changes were also explored in gingiva after tooth movement in conjunction with corticotomy.

\section{MATERIALS AND METHODS}

\subsection{Animals}

Twenty four nine-week-old, male Wistar rats, approximate weight $280 \mathrm{~g}$, from the Seoul National University vivarium were used. All animals were kept in stainlesssteel cages in air-conditioning and exposed to a 12-hour light/dark cycle. They were fed a pellet diet (Superfeed Co., Gangwon, Korea) and provided with tap water, both ad libitum. They were checked everyday in regard to their health status. The experimental protocol was approved by the committee for Animal Research Ethics, Seoul National University.

Four rats were killed as control at day 0 . In ten rats, corticotomy was performed on either left or right side and the remaining side was served as control, and killed at 7 and 14 days. In the remaining ten rats, maxillary right and left first molars were moved orthodontically; appliance and appliance in conjunction with corticotomy (appliance-corticotomy) were sequentially alternated between left and right sides and euthanized at 7 and 14 days.

\subsection{Experimental Procedures}

To move the maxillary first molar mesially, a constant force of $20 \mathrm{~g}$ was applied by a closed coil spring (Sentalloy, $0.009 \times 0.036$, Tomy Inc, Tokyo, Japan). The springs were attached to both the maxillary left first molar and the maxillary incisors using stainless steel ligature wires. Light-curing bonding material (3M Unitek, Nonrovia, CA, USA) was applied to perforations produced by a diamond bur along the mesiolingual and dislingual line angle of the maxillary left first molar and the distal sides of the incisors to ensure maximum retention of the coil spring (Figure 1). Reactivation was not done during the study period. In the groups receiving corticotomy, vertical and horizontal corticotomy cuts with flap reflection were performed through the cortical layer of the bone using a fine fissure bur (Figure 1). GluStitch (Glustitch Inc. Point Roberts, WA, USA) adhesive was applied to improve tissue adhesion around the wound area on rats receiving corticotomy. The weight of the animals was recorded on the day of the appliance insertion and immediately prior to euthanizing. All produres were performed using general anesthesia induced by subcutaneous injection of Zoletil (Virbac, Carros, France; Tiletamine $125 \mathrm{ml}$, Zolazepam $125 \mathrm{ml} ; 0.04 \mathrm{ml}$ ) and Rompun (Bayer AG, Leverkusen, German; Xylazire hydroxychloride $23.32 \mathrm{mg} / \mathrm{ml} ; 0.01 \mathrm{ml}$ ). At the end of an individual's experimental period, the animal was euthanized using an anesthetic overdose.

Following euthanasia, the gingiva on the compressed (mesial) side of the maxillary left first molar was excised, frozen in liquid nitrogen, and kept at $-80^{\circ} \mathrm{C}$ until used in real time PCR to quantify IL- $1 \alpha$ and TNF- $\alpha$.

\subsection{Real Time PCR}

\subsubsection{RNA Extraction}

TRIZOL reagent (Molecular Research Center, Inc., Cincinnati, OH, USA) was used to extract total RNA from each gingiva sample.

\subsection{2. cDNA Synthesis}

Two $\mu \mathrm{g}$ of total RNA was reverse transcribed into cDNA using a Promega reverse transcription (RT) system (Promega Corp., Madison, WI, USA). Reverse transcriptase was added to a mixture containing RT POX buffer, 2.5 $\mathrm{mM} \mathrm{MgCl}$, Oligo (dT) primer, dNTP Mix, and Rnasin. Once mixed, the reagents were incubated at $42^{\circ} \mathrm{C}$ for 60 mins, and then heated to $70^{\circ} \mathrm{C}$ for 15 mins.

\subsubsection{Real Time PCR}

Real time PCR was performed on an ABI 7900 HT Sequence Detection System using the SYBR-green fluorescence quantification system (Applied Biosystems,

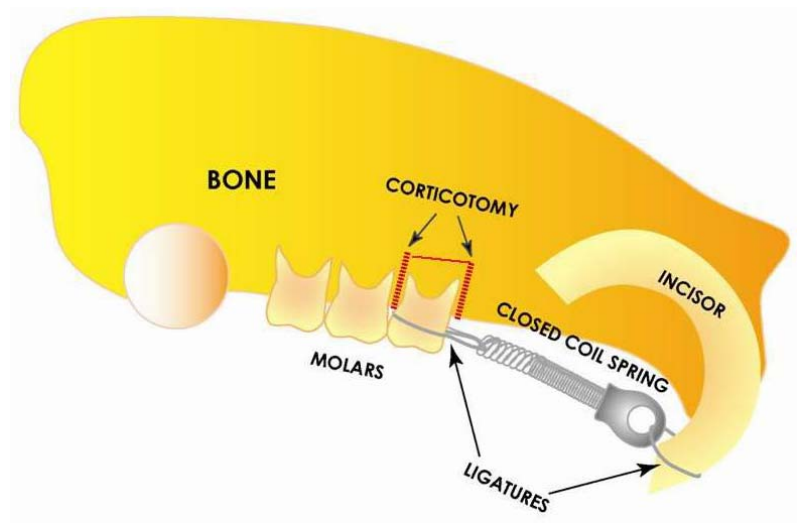

Figure 1. Schematic drawing: vertical and horizontal corticotomy cuts with flap reflection were placed after application of a coil spring. 
Foster City, CA, USA). The PCR conditions comprised 40 cycles: denaturing at $95^{\circ} \mathrm{C}$ for $30 \mathrm{sec}$, annealing at $60^{\circ} \mathrm{C}$ for $30 \mathrm{sec}$, extension at $72^{\circ} \mathrm{C}$ for $30 \mathrm{sec}$, followed by a standard denaturation curve. The primer sequences were as follows: IL-1 $\alpha$ (166 bp), 5'-TTTGCCCTCCTGT CCTTAAA-3'(forward) and 5'-TTGGAACCCAGAGG AAACAC-3' (reverse); TNF- $\alpha$ (190bp), 5'-GGGCTCA GAATTTCCAACAA-3' (forward) and 5'-GAGACAGC CTGATCCACTCC-3' (reverse). The SYBR Green PCR Mix (Applied Biosytems), $0.5 \mu \mathrm{l}$ template, and $0.8 \mu \mathrm{l}$ primer (forward + reverse) were used in each reaction. Calculations of the relative level of gene expression in the sample were made using the cycle threshold (CT) method. The mean $\mathrm{CT}$ values from three measurements were used to calculate the target gene expression with normalization to the internal control, glycerinaldehyde3-phosphate-dehydrogenase (GAPDH).

\subsection{Statistical Analysis}

Data were expressed as means \pm standard deviation (SD) and were analyzed using a Kruskal-Wallis one way analysis of variance on ranks, followed by Dunn's method for multiple comparisons. The Mann-Whitney Rank Sum test was used to test for differences between IL- $1 \alpha$ and TNF- $\alpha$ levels. A $p$ value $<0.05$ was required for statistical significance.

\section{RESULTS}

The orthodontically treated animals drank and ate less during the first $3-4$ days following treatment but then returned to normal food and water intake levels (data not shown). Their behavior did not appear to be affected by the orthodontic appliance, and their body weight increased over the experimental period (data not shown).

IL-1 $\alpha$ mRNA expression was detected in all of control specimens at day 0 (Figure 2). In the control group, IL-1 $\alpha$ levels remained similar during the 14 days, although they showed an insignificant decrease at day 14. For corticotomy group, IL- $1 \alpha$ mRNA expression was not significantly different compared to control group, while IL-1 $\alpha$ levels showed insignificant increase from day 7 to day 14 . Both the appliance group and the appliance-corticotomy group showed similar expression with controls and exhibited insignificant decrease from day 7 to day 14 . No differences were found between the appliance group and the appliance-corticotomy group.

TNF- $\alpha$ mRNA expression was also found in all of control specimen at day 0 (Figure 3). For corticotomy group, no differences were found compared to the control group. Both the appliance group and the appliance-corticotomy group showed statistically significant mRNA expression of TNF- $\alpha$ at day 7 compared to the control group and corticotomy group. There was no difference in TNF- $\alpha$

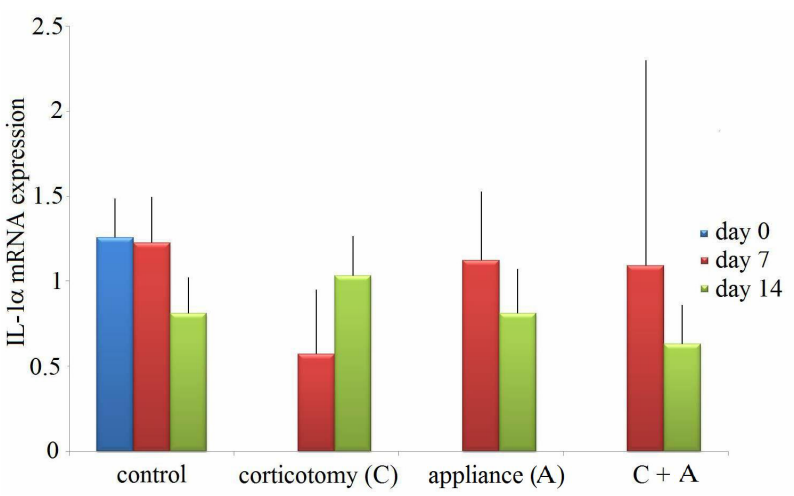

Figure 2. mRNA expression of IL-1 $\alpha$ (mean \pm standard deviation). Control, no appliance control; corticotomy, no appliance corticotomay; appliance (A), tooth movement using appliances; $\mathrm{A}+\mathrm{T}$, appliance-corticotomy.

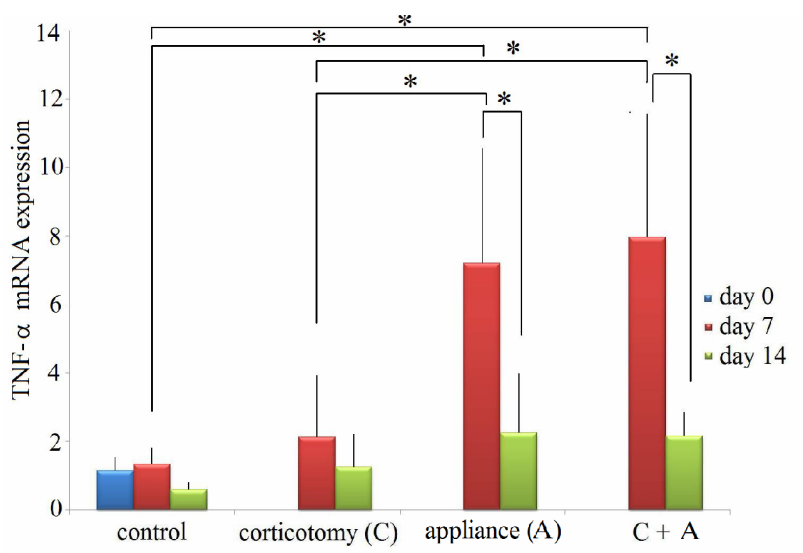

Figure 3. mRNA expression of TNF- $\alpha$ (mean \pm standard deviation). Control, no appliance control; corticotomy, no appliance corticotomay; appliance (A), tooth movement using appliances; A + T, appliance-corticotomy.

mRNA levels between the appliance group and the appliance-corticotomy group. At day 14, there were no differences between four groups. For both the appliance group and the appliance-corticotomy group, TNF- $\alpha$ mRNA expression significantly decreased from day 7 to day 14.

When compared between IL- $1 \alpha$ and TNF- $\alpha$ mRNA expression, the expression of TNF- $\alpha$ is statistically significant compared to that of IL- $1 \alpha$ in the appliance group at day 7 and in the appliance-corticotomy group at day 7 and day 14 (Table 1).

\section{DISCUSSION}

Many studies have explored cellular and subcellular changes occurring in the hard tissues after orthodontic force application, and it has been reported that various cytokines are detected in the PDL and alveolar bone following tooth movement $[5-7,14]$. This primary concern on hard tissues has resulted in less interest on changes in 
Table 1. IL- $1 \alpha$ and TNF- $\alpha$ mRNA expression.

\begin{tabular}{ccccc}
\hline & \multicolumn{2}{c}{ Day 7} & \multicolumn{2}{c}{ Day 14} \\
\cline { 2 - 5 } Group & IL-1 $\alpha$ & TNF- $\alpha$ & IL-1 $\alpha$ & TNF- $\alpha$ \\
\hline Control & $1.23 \pm 0.27$ & $1.34 \pm 0.49$ & $0.81 \pm 0.21$ & $0.59 \pm 0.23$ \\
Corticotomy (C) & $0.57 \pm 0.38$ & $2.13 \pm 1.81$ & $1.03 \pm 0.24$ & $1.26 \pm 0.96$ \\
Appliance (A) & $1.12 \pm 0.41$ & $7.2 \pm 3.36^{*}$ & $0.81 \pm 0.26$ & $2.25 \pm 1.73$ \\
C + A & $1.09 \pm 1.21$ & $7.96 \pm 3.62^{*}$ & $0.63 \pm 0.23$ & $2.16 \pm 0.70^{*}$ \\
\hline
\end{tabular}

Data are presented as mean \pm standard deviation. ${ }^{*} \mathrm{P}<0.05$ compared with TNF- $\alpha$ (Mann-Whitney Rank Sum Test) IL- $1 \alpha$, interleukin- $\alpha$; TNF- $\alpha$, tumor necrosis factor- $\alpha$.

soft tissues during tooth movement. However, soft tissue changes, frequently observed during orthodontic treatment, imply that gingival tissues may be involved in biological events related to bone remodeling following tooth movement [11]. In spite of this observation, few studies have shown cellular changes in gingiva following orthodontic treatment $[13,14]$. Here, real time PCR was used to investigate the mRNA expression of IL- $1 \alpha$ and TNF- $\alpha$ on the isolated gingiva after tooth movement. IL- $1 \alpha$, instead of IL- $1 \beta$, was selected in this study because IL- $\alpha$ is reported to be prominent in rodents while IL- $1 \beta$ is the major physiologic form of IL- 1 in humans [4]. mRNA expression of IL- $1 \alpha$ and TNF- $\alpha$ in mechanically compressed gingiva was used to provide information related to biological events occurring in gingival tissues. Additionally, mechanical tooth movement in conjunction with corticotomy was used to evaluate whether there was an effect on cytokine expression in gingiva of increased tooth movement over the same peod of observation.

The experimental observation periods were 7 and $14 \mathrm{~d}$ after treatment because of the following. First, a change in gingival contour may appear after a short-term amount of tooth movement. Second, differences in the amount of tooth movement between the appliance group and appliance-corticotomy group during a later stage of tooth movement may affect the amount of subcellular change in gingiva. Third, according to a preliminary study it takes $5-6 \mathrm{~d}$ for soft tissue to heal completely after corticotomy (data not shown). Thus, to exclude influences related to the healing process after corticotomy, an observation period of more than six days is needed. Finally, a gingival response during the early phase (3d) of tooth movement had been previously reported [14].

Interestingly, both IL- $1 \alpha$ and TNF- $\alpha$ mRNA were found in all control specimens. This was consistent with previous findings that gingiva constitutively stains for both IL- $1 \alpha$ and TNF- $\alpha$, implying that there is some degree of inflammation present in rat gingiva under normal conditions [14-16]. Furthermore, the results imply that IL- $1 \alpha$ and TNF- $\alpha$ may play important roles in tissue homeostasis and remodeling during normal physiological tooth drift. Rat molars drift distally under physiological conditions because the bony alveolar walls surrounding the roots undergo continuous formation on the mesial side and active resorption on the distal side [17]. Hower, the expression of IL- $1 \alpha$ and TNF- $\alpha$ mRNA on comessed gingiva showed different abundance changes after orthodontic loading. Upon application of an orthodontic force, IL- $1 \alpha$ levels did not change between groups, while TNF- $\alpha$ mRNA expression showed a significant increase.

IL- $1 \alpha$ levels in all of the groups in the present study failed to show significant increases at either 7 or $14 \mathrm{~d}$ compared to the control. A possible explanation for this observation is an inherent periodicity in IL-1 levels, meaning that IL- $1 \beta$ in the GCF returned to baseline level in 14-28 d [18]. On the other hand, the PDL of cat canines revealed that IL- $1 \alpha$ and $\beta$ level changes were detected at 12 and $24 \mathrm{~h}$ after orthodontic loading and reached a maximum after $3 \mathrm{~d}$ [7] Another study also reported that the expression of IL- $1 \beta$ and IL- 6 in the rat PDL reached a maximum value on day 3 after treatment [19]. Compared to IL- $1 \alpha$ levels in the PDL and alveolar bone, those in gingival fibroblasts following compressive force application showed significant increases for up to 8 hrs [20]. Moreover, it was demonstrated that IL- $1 \alpha$ expression in compressed rat gingiva was almost same as in the controls after 1 and $3 \mathrm{~d}$ [14]. Thus, IL-1 $\alpha$ in gingiva appears to express during a very early stage of orthodontic movement, which may explain the lack of an increase at day 7 and 14 in our study.

It has been reported that TNF- $\alpha$ levels were not detected in the compressed side PDL of rats on days 3, 7, and 10 [19]. However, TNF $\alpha$ mRNA levels strongly increased in rat PDL cells on day 10 [21]. In addition, pressured human PDL cells have shown statistically significant expression of TNF- $\alpha$ at day 7 [22]. In accordance with those results, a significantly increased expression of TNF $\alpha$ was found in the compressed gingiva at day 7 after orthodontic loading in this study. Taken together, these results suggest that TNF- $\alpha$ may act at a later stage of tooth movement. It was also notable that expression of TNF- $\alpha$ mRNA in our study returned to the baseline level at day 14 after orthodontic loading. As suggested for IL- $1 \alpha$, this suggests an inherent periodicity in TNF- $\alpha$ levels.

The evoked levels of IL- $1 \alpha$ and TNF- $\alpha$ in both the appliance group and the appliance-corticotomy group showed significantly differences in the present study. In contrast to this study, expression of IL- $1 \beta$ and TNF- $\alpha$ in compressed gingiva showed similar patterns at day 0 and 3 in the rat [14]. These conflicting results can be partly explained by involvement of these cytokines during different times. TNF- $\alpha$ appears to be expressed during later stages of tooth movement while IL- $1 \alpha$ is expressed more 
during early stages. It has also been reported that evoked levels of IL- $1 \beta$ and TNF- $\alpha$ in human GCF were similar at 7 and $21 \mathrm{~d}$ after tooth movement [23]. These different outcomes may be the result of a different expression pattern in PDL and resorbing bone than the expression pattern in gingiva.

It has been reported that the rate and amount of tooth movement after corticotomy is greater than that using mechanical force only. This is because there are less hyalinized areas following corticotomy, thus resulting in faster tooth movement [24]. Under such circumstances, different subcellular changes may be expected in the gingiva. In this study, however, the expression of IL-1 $\alpha$ and TNF- $\alpha$ mRNA in gingiva did not reflect differences related to tooth movement by appliance only and tooth movement by appliance in conjunction with corticotomy. It is possible that there were no differences between these two groups in their hyalinized zones due to the low level of force applied during the experiment [24]. Another explanation for this outcome is that increase of a number of osteoclast after corticotomy typically peaks at 1 to 2 months $[25,26]$. Thus, no differences between the appliance group and the appliance-corticotomy group may result from the experimental period of two weeks in the present study.

Finally, an additional control group, that with an appliance attached but without a force being applied, was excluded from this paper's results because another study (manuscript in preparation) showed no difference between that group and the control group. Thus, trauma from affixing the appliance used in this study would not be expected to cause expression of cytokines in gingival tissue at day 7 and 14. On the other hand, this study didn't include the early expression of gingiva during orthodontic treatment, which may have the important clue for relationship between gingiva and bone remodeling.

Elevated levels of IL- $1 \alpha$ and TNF- $\alpha$ in gingiva may implicate the participation of the gingiva in homeostasis and bone remodeling via paracrine pathway during orthodontic tooth movement. Clinical modification of gingiva contour during tooth movement can be partly explained by the finding that the gingiva appears to be involved in bone remodeling following tooth movement.

\section{CONCLUSION}

The results showed the presence of both IL- $1 \alpha$ and TNF- $\alpha$ in untreated gingiva at day 0 and increased expression of TNF- $\alpha$ in the pressure side gingiva at days 7 after orthodontic loading. The findings imply that gingival tissue may be involved in tissue homeostasis and bone remodeling.

\section{ACKNOWLEDGEMENTS}

This study was supported by new faculty settlement fund at Ewha
Womans' Univeristy.

\section{REFERENCES}

[1] Krishnan, V. and Davidovitch, Z. (2006) Cellular, molecular, and tissue-level reactions to orthodontic force. American Journal of Orthodontics \& Dentofacial Orthopedics, 129, 469e.1-469e.32.

[2] Dewhirst, F.E., Stashenko, P.P., Mole, J.E. and Tsurumachi, T. (1985) Purification and partial sequence of human osteoclast-activating factor: Identity with interleukin-1 beta. The Journal of Immunology, 135, 25622568.

[3] Bertolini, D.R., Nedwin, G.E., Bringman, T.S., Smith, D.D. and Mundy, G.R. (1986) Stimulation of bone resorption and inhibition of bone formation in vitro by human tumour necrosis factors. Nature, 319, 516-518. doi: $10.1038 / 319516 \mathrm{a} 0$

[4] Wang, C.Y. and Stashenko, P. (1993) The role of interleukin-1 alpha in the pathogenesis of periapical bone destruction in a rat model system. Oral Microbiology and Immunology, 8, 50-56.

doi:10.1111/j.1399-302X.1993.tb00543.x

[5] Vieleck, J. and Lee, T.H. (1991) Tumor necrosis factor, new insights into the molecular mechanisms of its actions. Journal of Biological Chemistry, 266, 7313-7316.

[6] Garlet, T.P., Coelho, U., Silva, J.S. and Garlet, G.P. (2007) Cytokine expression pattern in compression and tension sides of the periodontal ligament during orthodontic tooth movement in humans. European Journal of Oral Sciences, 115, 355-362.

doi:10.1111/j.1600-0722.2007.00469.x

[7] Davidovitch, Z., Nocolay, O., Ngan, P.W. and Shanfeld, J.L. (1988) Neurotransmitters, cytokines and the control of alveolar bone remodeling in orthodontics. Dental Clinics of North America, 32, 411-435.

[8] Uematsu, S., Mogi, M. and Deguchi, T. (1996) Interleukin (IL)-1 beta, IL-6, tumor necrosis factor-alpha, epidermal growth factor, and beta 2-microglobulin levels are elevated in gingival crevicular fluid during human orthodontic tooth movement. Journal of Dental Research, 75, 562-567. doi: $10.1177 / 00220345960750010801$

[9] Lee, K.J., Park, Y.C., Yu, H.S., Choi, S.H. and Yoo, Y.J. (2004) Effects of continuous and interrupted orthodontic force on interleukin-1 beta and prostaglandin E2 production in gingival crevicular fluid. American Journal of Orthodontics \& Dentofacial Orthopedics, 125, 168-177. doi:10.1016/j.ajodo.2003.03.006

[10] Lowney, J.J., Norton, L.A., Shafer, D.M. and Rossomando, E.F. (1995) Orthodontic forces increase tumor necrosis factor alpha in the human gingival sulcus. American Journal of Orthodontics \& Dentofacial Orthopedics, 108, 519-524. doi:10.1016/S0889-5406(95)70052-8

[11] Redlich, M., Shoshan, S. and Palmon, A. (1999) Gingival response to orthodontic force. American Journal of Orthodontics \& Dentofacial Orthopedics, 116, 152-158. doi:10.1016/S0889-5406(99)70212-X

[12] Beklen, A., Tüter, G., Sorsa, T., Hanemaaijer, R., Virta- 
nen, I., Tervahartiala, T. and Konttinen, Y.T. (2006) Gingival tissue and crevicular fluid co-operation in adult periodontitis. Journal of Dental Research, 85, 59-63. doi:10.1177/154405910608500110

[13] Ngan, P.W., Crock, B., Varghese, J., Lanese, R., Shanfeld, J. and Davidovitch, Z. (1988) Immunohistochemical assessment of the effect of chemical and mechanical stimuli on cAMP and prostaglandin E levels in human gingival fibroblasts in vitro. Archives of Oral Biology, 33, 163-174. doi:10.1016/0003-9969(88)90041-6

[14] Bletsa, A., Berggreen, E. and Brudvik, P. (2006) Interleukin-1alpha and tumor necrosis factor-alpha expression during the early phases of orthodontic tooth movement in rats. European Journal of Oral Sciences, 114,423-429. doi:10.1111/j.1600-0722.2006.00400.x

[15] Lossdörfer, S., Götz, W. and Jäger, A. (2002) Localization of IL-1alpha, IL-1 RI, TNF, TNF-RI and TNF-RII during physiological drift of rat molar teeth-An immunohistochemical and in situ hybridization study. Cytokine, 20, 7-16. doi:10.1006/cyto.2002.1970

[16] Miyauchi, M., Sato, S., Kitagawa, S., Hiraoka, M., Kudo, Y., Ogawa, I., Zhao, M. and Takata, T. (2001) Cytokine expression in rat molar gingival periodontal tissues after topical application of lipopolysaccharide. Histochemistry and Cell Biology, 116, 57-62.

[17] Ren, Y., Maltha, J.C. and Kuijpers-Jagtman, A.M. (2004) The rat as a model for orthodontic tooth movement-A critical review and a proposed solution. European Journal of Orthodontics, 26, 483-490. doi:10.1093/ejo/26.5.483

[18] Iwasaki, L.R., Haack, J.E., Nickel, J.C., Reinhardt, R.A. and Petro, T.M. (2001) Human interleukin-1 $\beta$ and interleukin-1 receptor antagonist secretion and velocity of tooth movement. Archives of Oral Biology, 46, 185-189. doi:10.1016/S0003-9969(00)00088-1

[19] Alhashimi, N., Frithiof, L., Brudvik, P. and Bakhiet, M. (2001) Orthodontic tooth movement and de novo synthesis of proinflammatory cytokines. American Journal of Orthodontics \& Dentofacial Orthopedics, 119, 307-312. doi:10.1067/mod.2001.110809

[20] Kook, S.H., Son, Y.O., Choe, Y., Kim, J.H., Jeon, Y.M., Heo, J.S., Kim, J.G. and Lee, J.C. (2009) Mechanical force augments the anti-osteoclastogenic potential of human gingival fibroblasts in vitro. Journal of Periodontal Research, 44, 402-410. doi:10.1111/j.1600-0765.2008.01121.X

[21] Yoshimatsu, M., Shibata, Y., Kitaura, H., Chang, X., Moriishi, T., Hashimoto, F., Yoshida, N. and Yamaguchi, A. (2006) Experimental model of tooth movement by orthodontic force in mice and its application to tumor necrosis factor receptor-deficient mice. Journal of Bone and Mineral Metabolism, 24, 20-27. doi:10.1007/s00774-005-0641-4

[22] Garlet, T.P., Coelho, U., Silva, J.S. and Garlet, G.P. (2007) Cytokine expression pattern in compression and tension sides of the periodontal ligament during orthodontic tooth movement in humans. European Journal of Oral Sciences, 115, 355-362. doi:10.1111/j.1600-0722.2007.00469.x

[23] Başaran, G., Özer, T., Kaya, F.A., Kaplan, A. and Hamamci, O. (2006) Interleukine-1 beta and tumor necrosis factor-alpha levels in the human gingival sulcus during orthodontic treatment. The Angle Orthodontist, 76, 830-836.

[24] Iino, S., Sakoda, S., Ito, G., Nishimori, T., Ikeda, T. and Miyawaki, S. (2007) Acceleration of orthodontic tooth movement by alveolar corticotomy in the dog. American Journal of Orthodontics and Dentofacial Orthopedics, 131, 448.e1-448.e8.

[25] Henrikson, P.A. (1968) Periodontal disease and calcium deficiency. An experimental study in the dog. Acta Odontologica Scandinavica, 26, 1-132.

[26] Sebaoun, J.D., Kantarci, A., Turner, J.W., Carvalho, R.S., Van Dyke, T.E. and Ferguson, D.J. (2008) Modeling of trabecular bone and lamina dura following selective alveolar decortication in rats. Journal of Periodontology, 279, 1679-1688. 